\title{
Competitive strategies for purchasing of cocoa by licensed buying companies in Ghana: The determinants and performance implications
}

\author{
John-Eudes Bakang, Alexander Annor Frimpong, Seth Etuah, Enoch Kwame Tham- \\ Agyekum*, Isaac Nii Sowah, Emmanuel Amponsah Doodo, Mark Amponsah, Evelyn Kyeraa \\ Boateng and Mariama Iddrisu
}

Department of Agricultural Economics, Agribusiness and Extension, Kwame Nkrumah University of Science and Technology-Kumasi, Ghana.

Received 3 August, 2021; Accepted 14 September, 2021

\begin{abstract}
This study explored the different competitive strategies used by the Licensed Buying Companies (LBC), the determinants of their choices and how it affected their performance. It also determined whether these strategies used influenced a farmer's decision to sell the cocoa beans to the LBCs as well as the constraints faced by farmers and the LBCS in doing business. Primary data was used for this study. Descriptive statistics and econometric models were used to analyze the objectives. From this study, prompt payment and use of accurate weighing scale were identified as the most effective competitive strategies with high cost of financing and lack of farm inputs and tools being the major challenges faced by the LBCs and farmers respectively. Good social relation of the purchase clerk, age of the farmer and the distance between the LBC and cocoa farmer had positive significant effects on cocoa farmers' decision in choosing a particular LBC. It is recommended that the government supports the LBCs with early financing to aid them in providing cocoa farmers with the needed inputs, tools and equipment to improve upon their outputs.
\end{abstract}

Key words: Licensed Buying Companies (LBC), Amansie West District, choice of LBC, cocoa purchases, competitive strategies, Ghana, return on investment.

\section{INTRODUCTION}

Ghana as a global burgeon in cocoa production is known as one of the finest producers of cocoa in the world. Cocoa production is the backbone of the Ghanaian economy for several years and it is the chief agricultural export (Gockowski et al., 2011). In Africa, cocoa production is dominated by four West African countries;

\footnotetext{
${ }^{*}$ Corresponding author. E-mail: ektagyekum@knust.edu.gh.
} 
Nigeria, Cameroon, Ghana and Cote d'Ivoire. Ghana is the second largest producer of cocoa beans in the world after the Ivory Coast and both countries produce over fifty percent of the world's cocoa (Vigneri, 2008; ObuobisaDarko, 2015; COCOBOD, 2011).

Cocoa production in Ghana is mainly done by smallholder farmers in the rural communities and it accounts for $30 \%$ of the total export earnings, providing income for about six million people (Anthonio and Aikins, 2009). The cocoa industry has been a major source of revenue for Ghana generating about $\$ 2$ billion annually and contributed to $14.5 \%$ of the total Gross Domestic Product as in 2018 (Ghana Statistical Service, 2019).

The contribution of the cocoa sector to the development of Ghana led to the introduction of COCOBOD, which was established by Government as a regulatory body for cocoa production and sales. Buying and exportation of cocoa was fully in the hands of Government through the Cocoa Marketing Board (CMB), a subsidiary of COCOBOD until 1992 when the cocoabuying market of Ghana was partially liberalized, allowing registered private companies in the purchasing of cocoa with the government regulating its price (COCOBOD, 2011). Subsidiary companies such as the CMC and Quality Control Company (QCC) were created to look after the marketing of cocoa and ensure that produce is of high quality respectively. Government introduced liberalization and privatization with the aim of improving the operational performance of the country's cocoa marketing system to ascertain higher and competitive prices (Abenyega and Gockowski, 2003; COCOBOD, 2011). The major LBCs in Ghana according to their share of the market are; Produce Buying Company; which is owned by the Government, AgroEcom Company Ltd, Olam, KuapaKooko Ltd., Adwumapa Buyers Ltd. (Owusu et al., 2017).

The objective of the liberalization was to introduce competition in the internal market and improve the chain with regard to its operational and financial performance as well as open up for the possibility of paying higher competitive producer prices (Ministry of Manpower, Youth and Employment, 2008). Privatization in its wake brought about the introduction and registration of both local and international Licensed Buying Companies (LBCs) responsible for purchasing cocoa beans from all the cocoa growing regions in the country (ICCO, 2006; COCOBOD, 2011). In most cocoa producing countries, the industry is fully liberalized, thereby not making use of LBCs. In Ghana, the Government decided to partially liberalize its cocoa industry so as to have some form of control over the activities that take place within the industry (Owusu et al., 2017). Since then, there has being an influx of LBCs in the cocoa buying industry, thereby increasing the market competition (Otchere et al., 2013; Owusu et al., 2017). For an LBC to be successful and gain competitive advantage over the others, it must have specific strategies which they can use to attract or convince farmers to sell their produce to them instead of their rivals and enabling them to stay competitive. The competitive strategy helps the LBC to gain competitive advantage and earn above average returns for its stakeholders. Competition arises where two or more LBCs offer their products and services to suppliers (Korsah et al., 2001). The LBCs evaluate all their strengths, weaknesses, opportunities and threats in order to stay in the competition (Otchere et al., 2013). According to Thompson et al. (2004), competitive strategy consists of approaches and initiative you take to attract customers, withstand competitive pressures and strengthen your market position.

All over the world, cocoa buying companies use various strategies to stay relevant in the cocoa market. In Ghana, the prices of cocoa produce are determined by the Government. The strategy is then to find other means to outperform their competitors. Instead of increasing the price at which they buy the produce, the LBCs in Ghana deal in offering incentives based on cash payments and non-economic incentives (Otchere et al., 2013). Cash incentives are popular in other parts of the world. Other packages may include services, credit, subsidized inputs and/or handing out small things ranging from soaps, pens and school books to Wellington boots, torches and machetes, depending on the amount of cocoa sold to the LBC (Vigneri and Santos, 2008), guaranteeing farmers an accurate scale (by having a standard weight at the depots), handing out annual farmer's awards, bonuses and "scratch lots" (with prices comprising anything from money to spraying items), and organizing farmer forums (Varangis and Schreiber, 2001).

Farmers tend to switch from one LBC to another due to the ineffective competitive strategies by the LBCs. There are high overhead costs and dwindling market share coupled with low profitability (Adjei-Ababio, 2011). Also, due to increasing competition within the industry, there is defrauding of smaller LBCs, breach of contract between farmers and LBCs, unfair influence by larger LBCs and the use of strategies which are beyond the capabilities of smaller LBCs that can lead to the collapse of the business or reduced profitability (Owusu et al., 2017).

A number of studies have been conducted in this area. For instance, Owusu et al. (2017) looked at whether competition in the Ghanaian cocoa industry was a bane or blessing for smaller LBCs. Ansah et al. (2018) studied the stake of License Buying Companies (LBCs) in Ghana in rethinking Ghana's Cocoa Quality. Adjei-Ababio (2011) evaluated the competitive strategies adopted by the LBCs in the cocoa industry in Ghana with a special focus on the Produce Buying Company Limited (PBC). Anang (2011) looked at the market structure and competition in the Ghanaian Cocoa Sector after partial liberalization. Currently, there is scanty information the competitive strategies being used by LBCs, the effects of the various 
competitive strategies on the performance of the LBCs, the factors that influences a farmer's choice of LBC and the constraints faced by both the farmers and LBCs. This study aims to fill this gap.

\section{METHODOLOGY}

This study was conducted in the Ashanti Region of Ghana with focus on the Amansie West District. Amansie West District is predominantly a rural area with agriculture as its main occupation with Manso Nkwanta as the district capital. The district lies between latitude $6^{\circ} 28^{\prime} \mathrm{N}$ and $1^{\circ} 53^{\prime} \mathrm{W}$ of the equator and longitude $6.467 \mathrm{~N}$ and $1.883^{\circ} \mathrm{W}$ of the Greenwich Meridian. The land covers an area of $1,364 \mathrm{~km}^{2}$. It has a population of about 144,110 of which $96.2 \%$ are rural and $3.8 \%$ are urban according to the 2010 population census. Its shares boundaries with Atwima Nwabiagya and Atwima Mponuah to the west, Bekwai Municipality and Amansie Central to the east, Upper Denkyira and Bibiani to the south and AtwimaKwawhoma to the north (mofa.gov.gh). The district has an agrarian economy and deals in the cultivation of oil palm, cocoa, orange and staple crops.

The study was conducted using both the primary data and secondary information. Primary data was obtained from the respondents, thus the LBCs and the farmers. The respondents were interviewed using a structured questionnaire. Primary data was collected from $7^{\text {th }}$ January to $16^{\text {th }}$ February 2021 . It was based on the competitive strategies that the LBCs use, the socioeconomic factors of the LBCs and farmers, the constraints faced by the LBCs in implementing their strategies and the factors that determine a farmers' choice of LBC. The secondary information for the study was obtained from COCOBOD, Kumasi.

A multi-stage sampling technique was used during this study. Purposive sampling was used to select 6 towns from the entire district. The LBCs chosen for the study were ten after a complete survey. Due to the unknown population of the farmers, Cochran's Formula was used to ascertain their sample size. Based on the calculation, the sample size obtained was 300. Afterwards, systematic random sampling was used to select a cocoa farmer from every third household from arbitrary street names created by researchers.

In analyzing the objectives of this study, both descriptive and inferential statistics were employed. Some of the econometric analysis employed were Multiple Linear Regression, Probit regression and Kendall's Coefficient of Concordance.

In assessing the effectiveness of the competitive strategies on the performance of the LBCs, the Return on Investment (ROI) was used as the basis for measuring performance of the LBCs. ROI is a ratio between net profit and cost of investment and it is usually used to evaluate the efficiency of an investment made by a firm. A higher $\mathrm{ROI}$ means that the profit gained compares favorably with the investment the company made. $\mathrm{ROI}=\mathrm{Net}$ profit/total investment $\times$ $100 \%$. Therefore, in calculating the ROI for the LBCs, the profit made for the 2019 marketing season was divided by the income they received from their mother companies for that same year in the District.

After the various strategies being used by the LBCs were known, they were grouped into two depending on the number of strategies the LBCs use, with the first group using more strategies (that is, 610) and the second group using less strategies (that is, 1-5). Afterwards, Multiple Linear Regression with one of the independent variables being used as a dummy was used to determine whether LBCs were getting higher or lower profits from their investment. Return on Investment was the dependent variable with the independent variables being the two groups of LBCs. Formula,
$Y=\alpha 0 X 0+\alpha 1 X 1+\alpha 2 X 2+\alpha 3 X 3+\alpha 4 X 4+\ldots \ldots . \alpha$ Xnth $+e_{i}$

$Y=$ the dependent variable will be the Return on Investment (ROI). $X=$ the independent variables, competitive strategies, $\alpha=$ coefficients to be estimated, $\mathrm{e}=$ error term.

In analyzing the factors that influence a farmers' choice of a LBC, the Probit regression was employed. Since there was more than one LBCs involved and many factors affecting their choice of LBC, the two groups of LBCs were used as the dependent variable and the independent variables being the socioeconomic factors and the competitive strategies. Hence, the formula,

$Y=\alpha 0 X 0+\alpha 1 X 1+\alpha 2 X 2+\alpha 3 X 3+\alpha 4 X 4+\ldots \ldots . \alpha$ Xnth $+e_{i}$

$\mathrm{Y}=$ the dependent variables will be the two groups of the LBCs.

$\mathrm{X}=$ the independent variables, socioeconomic factors and the competitive strategies, $\alpha=$ coefficients to be estimated, $e=$ error term.

LBC $=\alpha 0+\alpha 1$ Credit $+\alpha 2$ Subin $p+\alpha 3$ Bon $+\alpha 4$ Incom $+\alpha 5$ PPay $+\alpha 6$ SRel $+\alpha$ 7 YearOp+ai............e

Where the LBC denotes the various LBCs in the District

Credit denotes the provision of credit,

Subinp denotes subsidized inputs,

Bon denotes bonuses (GHS),

Incom denotes income of the LBCs,

PPay denotes prompt payment

SRel denotes social relation of PC and

YearOp denotes years of operation.

\section{Description of variables}

\section{Income of the $L B C$}

The larger the amount of income that an LBC has, the ease with which they are able to pay farmers and provide them with extra benefits. This therefore, has a positive influence on the farmers' in choosing an LBC.

\section{Bonuses}

Bonuses are expected to have a positive effect on farmers' choice of LBC. Since the price at which the cocoa beans are purchased are the same across all of the LBCs, farmers will likely sell their produce to those who are able to add some extra amount of money to the actual price.

\section{Subsidized inputs}

Providing farmers with tools and equipment for farming helps to convince them to choose an LBC which is able to supply them with such tools. Therefore, this strategy exerts a positive influence on the LBC a farmer will choose.

\section{Provision of credit}

This will have a positive effect on the LBC a farmer will choose. This is because due to the seasonality of production, farmers most often than not exhaust their incomes, so likely will they choose an LBC that provides them with some credit for their personal use.

\section{Prompt payment}

This deals with how quick farmers are being paid when their beans 
are purchased. This has a positive influence on the farmer's choice of LBC because they are likely to choose an LBC which pays them immediately and not those who take a long period of time settling their payment.

\section{Years of operation of the $L B C$}

Years of operation has a positive influence on a farmers' choice of LBC. This is because; the longer the number of years the LBC has been in operation the more trustworthy they are to work with.

NB: A positive a priori expectation shows a direct relationship between the variables identified and the choice of LBCs. A negative a priori expectation shows an inverse relationship between the dependent variables and the independent variables stated.

In analyzing the constraints associated in the implementation of these strategies, data was obtained on the challenges faced by both the farmers and the LBCs. In identifying the severity of the challenges, they were asked to rank them on a scale of 1 to 4 . The Kendall's coefficient of concordance (W) was used to analyze how the various respondents agree to the ranked challenges. The identified challenges were ranked from the most pressing to the least pressing using the rank numerals $1,2,3$ and $4,1=$ the most pressing challenge and $4=$ the least pressing challenge. The challenge with the least total score was ranked as the most pressing while the challenge with the highest total score was ranked the least pressing. The coefficient of concordance was calculated within the range of 0 to 1 using the calculated total rank. A coefficient of 1 represents a complete agreement among respondents to the ranked challenges while 0 represents a complete disagreement to the ranked challenges among respondents.

\section{RESULTS AND DISCUSSION}

\section{Socioeconomic characteristics of farmers}

The average age of farmers interviewed was 49.81 years with the maximum being 85 whilst the minimum age was 23 years. The average age of 50 years is almost the same as Ghana's national average age of 50years for cocoa farmers (Lowe, 2017). This shows that, even though most of the cocoa farmers in Amansie West District are in the working class, they still have an aged population of cocoa farmers (Table 1).

The average household size was five people in the study area, with the maximum being eleven people and the minimum being one person. The minimum and maximum farm sizes of respondents were 1 and 40 ha respectively with an average farm size of 7.48 ha.

In terms of the quantity of cocoa produced, the average production was 9 bags, with the minimum and maximum quantity produced being one bag and seventyfive bags respectively. Most of the farmers (56.67\%) had only basic education, over $30 \%$ had no education, with only 8 and $4 \%$ having secondary and tertiary education respectively. This is in agreement with the GSS (2010) population and housing census which showed that $63 \%$ of the people in Amansie West District had only basic education.

\section{Socioeconomic Characteristics of Licensed Buying Companies (LBCs)}

Ten LBCs operating in the Amansie West District (AWD) were used in this study. The maximum number of years an LBC has been operating in the district was thirty, the minimum number of years was four and thirteen years being the average. From the last cocoa season, an average of 16,787 bags of cocoa beans was purchased with 1,950 and 45,235 bags being the minimum and maximum bags purchased respectively. Also, the minimum number of farmers associated with an LBC was 300 , with the average being 563 while the maximum was 1,000 farmers (Table 2).

For the LBCs in the District, the average income was GHC 8,685,157 with the maximum and minimum being GHC 1,029,550 and $\mathrm{GHC} 23,351,745$ respectively whilst the average cost was also $\mathrm{GHC} 8,672,157$. The minimum cost was GHC 1,022,050 and the maximum cost was GHC 23,329,245. In terms of the Net Profit, the maximum was $\mathrm{GH} \mathbb{C} 22,500$ with an average and minimum profit of $\mathrm{GH} \Phi$ 13,000 and $\mathrm{GH} \Phi$ 7,500 respectively.

\section{Competitive strategies used by the licensed buying companies}

Owusu et al. (2017) established the fact that there is competition in the cocoa industry among the LBCs. However, the existing competition in the domestic cocoa industry is a bane to the business operations of smaller LBCs in the industry. The LBCs in the district were therefore asked about the competitive strategies they were using in order to get the farmers to sell their produce to them. The strategies were listed and the LBCs were asked to choose whether or not they used any of the listed strategies. LBC in Ghana are not able to use price based strategies since the produce has a fixed price (Otchere et al., 2013) so the strategies listed were mostly non-price based. What is interesting is that the COCOBOD only sets a floor price, which means that technically, buying companies could pay farmers prices higher than the producer price (Vigneri and Santos, 2007). But LBCs rarely pay farmers a price above the floor price. They however, compete through non-price mechanisms like the provision of incentives, input subsidies and cash rewards to farmers (Figure 1). A mean score of 1.0 shows that all the ten LBCs use that particular strategy. From Figure 1, it could be seen that prompt payment and the use of accurate weighing scale were agreed on by all the ten LBCs. According to Laven (2007), farmers are willing to sell their beans to the LBCs if they will be paid immediately after the sale of the produce.

Provision of credit and provision of extension services were the least used strategies among the LBCs. 
Table 1. Socioeconomic characteristics of farmers.

\begin{tabular}{lcccc}
\hline Variable N (300) & Minimum & Maximum & Average & Std. Dev. \\
\hline Age of respondents & 23 & 85 & 49.81 & 12.22 \\
Household size & 1 & 11 & 4.47 & 2.09 \\
Farm Size (ha) & 1 & 40 & 7.48 & 5.99 \\
Years of Farming & 1 & 50 & 18.28 & 10.28 \\
Quantity Produced (bags) & 1 & 75 & 8.94 & 8.96 \\
& & Frequency N (300) & Percentage \\
& No formal & 91 & \multicolumn{2}{c}{30.33} \\
Educational Level & Basic & 173 & \multicolumn{2}{c}{57.67} \\
& Secondary & 24 & \multicolumn{2}{c}{8.00} \\
& Tertiary & 12 & & \multicolumn{2}{c}{4.00} \\
\hline
\end{tabular}

Source: Field data (2020).

Table 2. Socioeconomic characteristics of the LBC.

\begin{tabular}{lcccc}
\hline Variable & Min & Max & Average & Std. Dev. \\
\hline Years of operation & 4 & 30 & 13.4 & 7.18 \\
Quantity purchased (bags) & 1950 & 45235 & 16787.4 & 15575.82 \\
Number of farmers & 300 & 1000 & 563 & 260.73 \\
Income $(\mathrm{GHC})$ & 1029550 & 23351745 & 8685157 & 8027292 \\
Total cost $(\mathrm{GHC})$ & 1022050 & 23329245 & 8672157 & 8022854 \\
Net profit $(\mathrm{GHC})$ & 7500 & 22500 & 13000 & 5502.53 \\
Return on Investment (\%) & 0.08 & 1.13 & 0.347 & 0.36 \\
\hline
\end{tabular}

Source: Field Data (2020), NB: 6 GHC $=1 \$$.

Bonuses, provision of subsidized inputs, provision of farm tools and involvement of purchasing clerks in farmers' social activities were all used by a greater proportion of the Licensed Buying Companies in the districts. The discussion so far proves that cocoa farmers choose LBCs because of the offer of prompt payment of cash and the use of accurate weighing scale. The choice of LBCs is largely driven by the offer of prompt cash by any LBC and credit supply. Cash constrained farmers may choose buyers based on their ability to get a full cash payment for their produce and possibly, some loan to finance productive activities (Vigneri and Santos, 2009).

\section{Assessing the effectiveness of the competitive strategies on the performance of the LBCs}

Return on investment was used in measuring the performance of the LBCs. From Table 3, it can be seen that both provision of farm tools and involvement of PC in social activities of farmers had a significant level of $5 \%$ and a coefficient of 0.523 and 0.494 respectively indicating that adoption of these will lead to an increase in the Return on Investment. Again, prompt payment was significant at $10 \%$ with a positive coefficient of 0.752 which shows that when a company adopts the prompt payment strategy, their ROI will also improve. These support the findings of Laven (2007) whose results indicated LBCs who adopt these three strategies (provision of farm tools and involvement of PC in social activities of farmers and prompt payment) attract more farmers which leads to an increase in their Return on Investment.

Adjei-Ababio (2011) evaluated the competitive strategies adopted by the PBC. The impact of the prudent formulation and implementation of strategic planning on the performance of PBC showed a steady increase of the market share of PBC from 30 percent in 2007/2008 crop season to approximately $37 \%$ in $2010 / 2011$ crop season. The report indicate that the occurrences of cocoa shortages have reduced from $0.53 \%$ of total purchases in $2007 / 2008$ to about $0.25 \%$ in the $2009 / 2010$ season. Profit margin has moved positively from 6.87 percent in $2007 / 2008$ to 18.57 percent in 2009/2010. Debt/Equity Ratio has improved considerably from $103.6 \%$ in $2007 / 2008$ to $43.62 \%$ in $2009 / 2010$. 


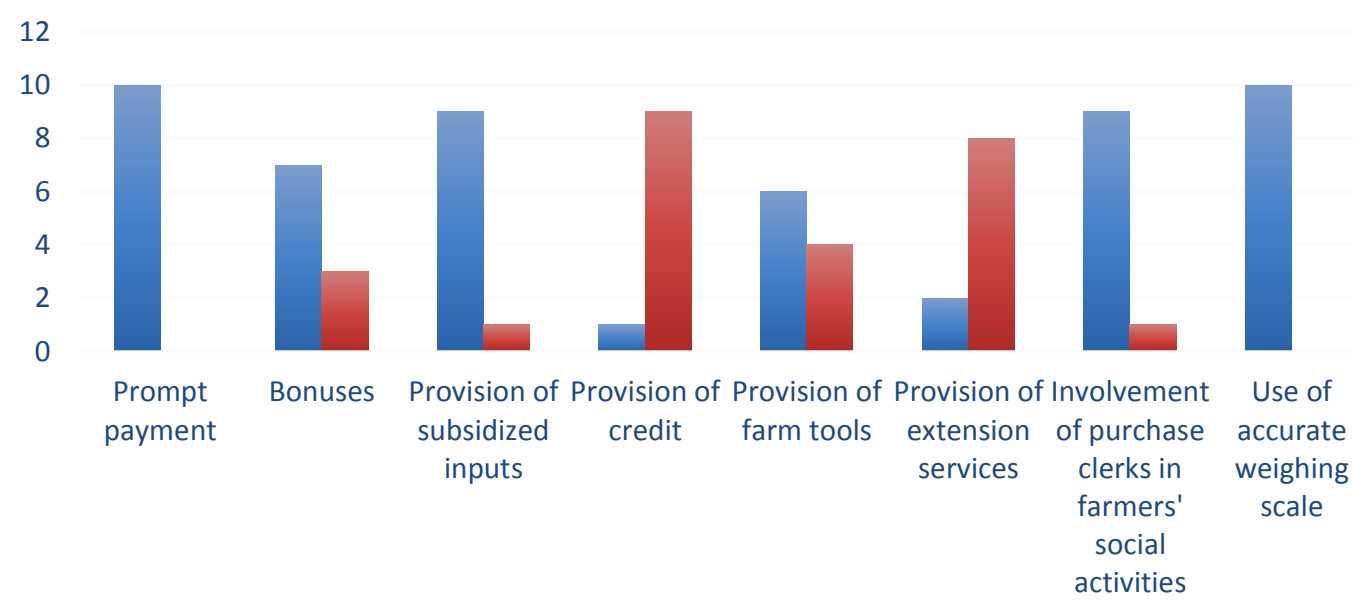

Yes $\square$ No

Figure 1. Strategies used by the LBCs. Source: Field data (2020).

Table 3. Effects of competitive strategies on the performance of the LBCs.

\begin{tabular}{lccc}
\hline Variables & Coefficient & Std. error & Sig. \\
\hline (Constant) & 0.35 & 1.08 & 0.78 \\
Bonuses & -0.65 & 0.74 & 0.47 \\
Prompt payment & $0.75^{\star}$ & 0.58 & 0.08 \\
Provision of credit & 0.16 & 0.74 & 0.85 \\
Provision of farm tools & $0.52^{* *}$ & 0.74 & 0.03 \\
Provision of extension services & -1.09 & 0.95 & 0.37 \\
Involvement of PC in social activities of farmers & $0.49^{* \star}$ & 0.60 & 0.02 \\
Accurate weighing scale & 0.57 & 0.88 & 0.54 \\
Provision of subsidized inputs & -0.11 & 0.74 & 0.89 \\
Number of observation= 10 & & & \\
F=0.322 & & & \\
Adjusted $\mathrm{R}^{2}=0.499$ & & & \\
\hline
\end{tabular}

** and * represent significance at 5 and $10 \%$ probability level, respectively. Source: Field data (2020).

\section{Factors that influence a farmers' choice of a LBC}

In order to find the factors that influence the farmers, the LBCs were group into two, the first group were the LBCs that used six or more competitive strategies and the second group were the LBCs that used less than five competitive strategies. The competitive strategies along with some socioeconomic characteristics were used as the independent variables whilst the two groups of LBCs were the dependent variables (Table 4).

The absence of price competition between buyers has meant that selection of LBCs by farmers is based on a variety of non-price factors including the mode of payment and the provision of other services (Vigneri and Santos, 2009). From Table 4, it was revealed that good social relation of the purchase clerk had a significant impact $(10 \%)$ on the farmers' decision in choosing a particular LBC. This result is in line with the findings of Owusu et al. (2017), that states that to attract more farmers, an LBC should select a purchase clerk who is well known and is able to relate well with others in a community. Laven (2007) also agrees that farmers' choice of LBCs is influenced by social relationship with the purchasing clerk. Also, both the age of the farmer and the distance between the LBC and cocoa farmer had a positive significant level of 5 and $10 \%$ respectively. This 
Table 4. Factors that influences a farmer's choice of LBC.

\begin{tabular}{lccc}
\hline Parameter & Coefficient & Std. error & Sig. \\
\hline (Intercept) & -2.98 & 0.66 & 0.00 \\
Age & $0.06^{\star \star}$ & 0.00 & 0.02 \\
Gender & 0.13 & 0.13 & 0.42 \\
Distance to the LBC & $0.36^{\star}$ & 0.24 & 0.06 \\
Years of operation & 0.25 & 0.10 & 0.36 \\
Good social relation of the Purchase clerk & $0.40^{\star}$ & 0.32 & 0.08 \\
\hline
\end{tabular}

** and * represent significance at 5 and $10 \%$ probability level, respectively.

Source: Field data (2020).

means that an increase in the age of a cocoa farmer and the distance between the LBC and cocoa farmer significantly influence their choice of LBC. Adjei-Ababio (2011) agrees to the point that in responding to the competition; agency proximity was also favourable.

Despite the increase in number of buyers at the village level, farmers' choice of buyer seems to be increasingly restricted to only one buyer. This means that once they are comfortable with a particular LBC, it becomes difficult to change unless they are enticed with huge incentives (Vigneri and Santos, 2009). The introduction of internal competition has led to several benefits to farmers attesting that privatization is beneficial to farmers (Akiyama et al., 2001; Akayima et al., 2003; Gilbert, 2009). Private competition has benefitted farmers because LBCs have sought to win producer loyalty by providing services such as inputs on credit, subsidies for inputs as well as the provision of loans (Varangis and Schreiber, 2001).

\section{Constraints faced by the LBCs}

From Table 5, it can be seen that high cost of financing was the major constraint faced by the LBCs. For an LBC to be able to purchase more cocoa, it needs a huge sum of money in order to do so and to perform their other functions and also, the cost associated with borrowing in Ghana is really high in the finance market which makes it difficult for an LBC to survive in the industry. This constraint reconciles with the findings by Asante (2014) which states that high cost of financing is major problem for LBCs. Adjei-Ababio (2011) agrees to the point of high finance cost. High cost of borrowing to finance cocoa purchases is incurred due to inadequate seed funds from COCOBOD and low recycling rates, huge sums of money will have to be borrowed from local commercial banks at exorbitant interest rates. Finance charges represent about 30 percent of the total operational costs of the company.

The high cost of financing was followed by poor road networks which was ranked second. The LBCs complained that most of the road networks leading to the various cocoa farming communities were really bad making it hard to get access to the cocoa farms and mostly resulting in an increase in maintenance cost of vehicles. Disloyalties on the part of farmers and poor fermentation or drying of beans were ranked third and fourth respectively. LBCs also complained that some farmers, after being provided with the inputs or materials needed to aid them with their production and sometimes even providing them with credit, decide not to sell the beans to them to evade paying back the loan and in turn sell it to other competitors. Also, for farmers to gain more money, they do not properly dry the cocoa beans in order to increase its weight since the price of a bag depends on the weight of it. There was a seventy percent level of agreement among the Licensed Buying Companies which was significant at one percent.

\section{Constraints faced by the farmers}

Table 6 shows the constraints faced by cocoa farmers in the Amansie West District. The major constraint they faced was lack of input and tools for farming. The farmers made a complaint that they were not getting access to the needed inputs such as fertilizers, chemicals for treating pests and diseases and tools such as wellington boots, spray machines which has not enabled them to work efficiently. This was followed by low produce price which was ranked second. Currently, farmers are being paid $\mathrm{GH} \mathbb{C} 515$ per $63.5 \mathrm{~kg}$ bag of cocoa which they consider that to be very low. Furthermore, the farmers added that, since the price of the produce is low they are not able to cater for their personal expenses as well as purchase the needed materials for farming. The availability of cash with regard to inputs such as labour and chemicals is important in the production of cocoa. Farmers are generally liquidity-constrained and need credit in order to maintain or expand production. Many LBCs are reluctant to provide credit since they mistrust 
Table 5. Constraints faced by the LBCs.

\begin{tabular}{lcc}
\hline Variables & Mean score & Rank \\
\hline High cost of financing & 1.30 & $1^{\text {st }}$ \\
Poor road networks & 1.90 & $2^{\text {nd }}$ \\
Disloyalty of farmers & 3.20 & $3^{\text {rd }}$ \\
Poor fermentation or drying & 3.60 & $4^{\text {th }}$ \\
$\mathrm{N}$ & 10 & \\
Kendall's W & \\
Chi-Square $_{\text {a }}$ & 0.70 & \\
Df & 21.00 & \\
Asymp. Sig. & 3 & \\
\hline
\end{tabular}

Source: Field data (2020).

Table 6. Constraints faced by the farmers.

\begin{tabular}{lcc}
\hline Variables & Mean score & Rank \\
\hline Lack of inputs and tools for farming & 1.29 & $1^{\text {st }}$ \\
Low produce price & 2.32 & $2^{\text {nd }}$ \\
Difficult in transporting cocoa beans from farm & 2.98 & $3^{\text {rd }}$ \\
Inability on the part of LBCs to fulfill their promises & 3.42 & $4^{\text {th }}$ \\
$N$ & 300 & \\
Kendall's W & 0.52 & \\
Chi-Square & 464.79 & \\
Df & 3 & \\
Asymp. Sig. & 0.00 & \\
\hline
\end{tabular}

Source: Field data (2020).

farmers. If the LBCs give farmers credit in return for a guarantee of cocoa, it cannot be guaranteed that the farmers will supply the cocoa to them and not to their competitors (Vigneri and Santos, 2008; Abenyega and Gockowski, 2003).

The farmers further stated that after harvesting the cocoa beans on the farm, they find it difficult to bring it home since it is difficult to get access to the farms using vehicles; therefore, they mostly have to carry it home over long distances. Inability on the part of LBCs to fulfill their promises which was ranked fourth was the least constraint faced by farmers in the district. There was fiftytwo percent $(52 \%)$ level of agreement among farmers which was significant at $1 \%$.

\section{CONCLUSION AND RECOMMENDATION}

Cocoa purchases, due to its lucrativeness has become one of the most competitive businesses in Ghana, hence the increased competition among the LBC to gain the greatest share of the market. As such, this study identified the various competitive strategies used by the LBCs and it shows that the most adopted strategies were prompt payment (1.0) and the use of accurate weighing scale (1.0) used in addition to other strategies. Therefore, it makes it important for an LBC to combine a variety of competitive strategies to better meet the needs of cocoa farmers to gain their loyalty. The more strategies a company uses, the more farmers were willing to sell their produce to the LBC which in the end, had a positive impact on the Return on Investment of the LBC. Competitive strategies such as prompt payment (10\%), involvement of purchase clerk in the social activity of the farmers $(5 \%)$ and provision of farm tools to farmers (5\%) all had a significant impact on the Return on Investment. In order to influence a cocoa farmer's decision to choose a particular LBC, it is important for the LBC to choose a purchase clerk who has a good social relation with the farmers. In addition to this, the distance between the farmers and the LBC and the farmers' age are also key to their decision. The most severe challenge being faced by the LBCs is high cost of financing $\left(1^{\text {st }}\right)$, followed by poor road networks $\left(2^{\text {nd }}\right)$ and disloyalty on the part of farmers 
$\left(3^{\text {rd }}\right)$. For the farmers, their major constraint was lack of inputs and tools for farming which impedes the quantity and quality of their produce.

The study recommends that the Government through COCOBOD will offer support to the LBCs with early financing to aid them in performing their activities as well as providing the farmers with the needed inputs, tools and equipment to improve upon their outcome or output. LBCs should adopt competitive strategies like prompt payment, use of accurate scale, provision of farm tools and subsidized inputs and purchase clerks with good social relation skills to help attract more farmers to sell their cocoa beans to them which will help them to improve their profits. It is also important for the LBCs to adopt a variety of competitive strategies to better meet the needs of cocoa farmers to gain their loyalty. Since cocoa is an important backbone to the economy of Ghana, COCOBOD should provide farmers with inputs and tools such as cutlass, spraying machine, fertilizers, herbicides and insecticides to aid in them in farming. This will help alleviate a major constraint of cocoa farmers.

\section{CONFLICT OF INTERESTS}

The authors have not declared any conflict of interests.

\section{REFERENCES}

Abenyega O, Gockowski J (2003). Labour practices in the cocoa sector of Ghana: with a special Achieve: The Case of Cocoa in Ghana. GSSP Background Paper, International Food Policy.

Adjei-Ababio K (2011). Evaluation of competitive strategies of the licensed buying companies (LBCs) in Ghana: A case study of the Produce Buying Company Ltd (PBC). A Thesis submitted to the Institute of Distance Learning, Kwame Nkrumah University of Science and Technology in partial fulfilment of the requirements for the award of the degree of Commonwealth Executive Master in Business Administration.

Akayima T, Baffes J, Larson D, Varangis $P$ (2003). Commodity market reform in Africa: Some recent experience. World Bank Policy Research Working Paper 2995.

Akiyama T, Baffes J, Larson D, Varangis P (2001). Market Reforms: Lessons from Country and Commodity Perspectives. 2001. In: Akayima, T., J. Baffes, D. Larson and P. Varangis (Eds.), Commodity Market Reforms: Lessons of Two Decades. The World Bank, Washington, D.C. pp. 5-33.

Anang BT (2011). Market Structure and Competition in the Ghanaian Cocoa Sector after Partial Liberalization. Current Research Journal of Social Sciences 3(6):465-470.

Ansah GO, Ofori F, Siaw LP (2018) Rethinking Ghanas Cocoa Quality: The Stake of License Buying Companies (LBCs) in Ghana. Journal of Agri Science and Food Research 9(224):2.

Anthonio DC, Aikins ED (2009). Reforming Ghana's cocoa sector: an evaluation of private participation in marketing. Master Thesis, Continuation course Marketing and E-commerce Department of Business Administration and Social Sciences Division of Industrial Marketing and E-commerce, Luleå University of Technology.

Asante BE (2014). Effect of storage and transportation challenges of LBCs on the quality and postharvest losses of cocoa beans from Enchi A, Enchi and Sefwi Wiawso cocoa districts in the Western Region of Ghana. A thesis submitted to the school of research and graduate studies, Kwame Nkrumah University of Science and Technology, Kumasi-Ghana.
COCOBOD (2011). The Cocoa Industry, Ghana Cocoa Board (COCOBOD), Retrieved from http://www.cocobod.gh

Gilbert CL (2009). Cocoa market liberalization in retrospect. Review of Business Economics 54(3):294-312.

Gockowski J, Afari-Sefa V, Sarpong DB, Osei-Asare YB, Dziwornu AK (2011). Increasing income of Ghanaian cocoa farmers: Is introduction of fine flavour cocoa a viable alternative. Quarterly Journal of International Agriculture 50(2):175-200.

Ghana Statistical Service (GSS) (2010). Population and Housing Census, National Analytical Report, Ghana Statistical Service.

Ghana Statistical Service (GSS) (2019). Ghana Statistical Service, April ed., Ghana. https://mofa.gov.gh/site/sports/districtdirectorates/ashanti-region/148-amansie-west

International Cocoa Organization (ICCO) (2006). Assessment of the movement of global supply and demand. Market Committee, $6^{\text {th }}$ meeting. Retrieved from: http://www.icco. org/economics/consultive.aspx

International Cocoa Organization (ICCO) (2011). The World Cocoa Economy: Past and Present, International Cocoa Organisation, Bloomsbury House.

Korsah KB, Nyarko EK, Tagoe NA (2001). Impact of Financial Sector Liberalization on Competition and Efficiency in the Ghanaian Banking Industry. Copyright, International Labour Organization 2001.

Laven A (2007). Marketing Reforms in Ghana's Cocoa Sector. ODI Background Note. Retrieved from http://www.wiego.org/publications/Chains\%20of\%20Fortune\%20Chapt ers/

Ministry of Manpower, Youth and Employment (2008). Labour Practices in Cocoa Production in Ghana (Pilot Survey)

Obuobisa-Darko E (2015). Cocoa Research Innovations and Output in Ghana. Journal of Economics and Sustainable Development 6(8/12):12-21.

Otchere AF, Annan J, Anin EK (2013). Achieving Competitive Advantage through Supply Chain Integration in the Cocoa Industry: A Case Study of Olam Ghana Limited and Produce Buying Company Limited. International Journal of Business and Social Research 3(2):131-145

Owusu AG, Antwi I, Siaw LP (2017) All because of competition: A bane or blessing for smaller licence buying companies (LBCs) of the Ghanaian cocoa industry. Cogent Business \& Management 4:1299603.

Thompson JAA, Gamble JE, Strickland AJ (2004). Strategy: Winning in the Marketplace: Core Concepts, Analytical Tools, Cases. New York, McGraw Hill. Tiffen\%20MacDo

Varangis $P$, Schreiber $G$ (2001). Cocoa market reforms in West Africa. In A. Vázquez Barquero (Ed.), Desarrollo, redes e innovación: lecciones sobre desarrollo endógeno, Development, networks and innovation: Lessons on endogenous development, Madrid: Ediciones Pirámide pp. 35-82.

Varangis P, Schreiber G (2001). Cocoa Market Reforms in West Africa. In: Akayima T, Baffes J, Larson D, Varangis $P$ (Eds.), Commodity Market Reforms: Lessons of Two Decades. The World Bank, Washington, D.C. pp. 35-82.

Vigneri M (2008). Drivers of Changes in Ghana's cocoa Sector. Accra: International Food Policy Research Institute.

Vigneri M, Santos P (2008). What does liberalization without price competition. Wageningen: Wageningen University and Research Centre.

Vigneri M, Santos P (2009). What Does Liberalization without Price Competition Achieve? The Case of Cocoa in Ghana. Contributed Paper prepared for presentation at the International Association of Agricultural Economists Conference, Beijing, China 16-22:14-15. 